EGU21-10203

https://doi.org/10.5194/egusphere-egu21-10203

EGU General Assembly 2021

(c) Author(s) 2021. This work is distributed under

the Creative Commons Attribution 4.0 License.

\title{
Organic pollutants from Indonesian peatland fires: regional influences and its impact on lower the stratospheric composition
}

\author{
Simon Rosanka ${ }^{1}$, Bruno Franco ${ }^{2}$, Lieven Clarisse ${ }^{2}$, Pierre-François Coheur ${ }^{2}$, Andreas Wahner ${ }^{1}$, and \\ Domenico Taraborrelli ${ }^{1}$ \\ ${ }^{1}$ Institute of Energy and Climate Research, IEK-8: Troposphere, Forschungszentrum Jülich GmbH, Jülich, Germany \\ ${ }^{2}$ Spectroscopy, Quantum Chemistry and Atmospheric Remote Sensing (SQUARES), Université libre de Bruxelles (ULB), \\ Brussels 1050, Belgium
}

In 2015, the particularly strong dry season in Indonesia, caused by an exceptional strong El Niño, led to severe peatland fires. Due to the high carbon content of peatland, these fires are characterised by high volatile organic compound (VOC) biomass burning emissions. The resulting primary and secondary pollutants are efficiently transported to the upper troposphere/lower stratosphere (UTLS) by the developing Asian monsoon anticyclone (ASMA) and the general upward transport in the intertropical convergence zone (ITCZ). In this study, we assess the importance of these VOC emissions for the composition of the lower troposphere and the UTLS by performing multiple chemistry simulations using the global atmospheric model ECHAM/MESSy (EMAC). In a first step, we find that EMAC properly captures the exceptional strength of the Indonesian fires based on the comparison of modelled columns of the biomass burning marker hydrogen cyanide $(\mathrm{HCN})$ to spaceborne measurements from the Infrared Atmospheric Sounding Interferometer (IASI). In the lower troposphere, the increase in VOC levels is higher in Indonesia compared to other biomass burning regions. This directly impacts the oxidation capacity and leads to a high reduction in hydroxyl radicals $(\mathrm{OH})$ and nitrogen oxides $\left(\mathrm{NO}_{x}\right)$. In general, an increase in ozone $\left(\mathrm{O}_{3}\right)$ is predicted close to the peatland fires. However, particular high concentrations of phenols lead to an $\mathrm{O}_{3}$ depletion in eastern Indonesia. By employing the detailed in-cloud OVOC oxidation scheme Jülich Aqueous-phase Mechanism of Organic Chemistry (JAMOC), we find that the predicted changes are dampened and that by ignoring these processes, global models tend to overestimate the impact of such extreme pollution events. The upward transport in the ASMA and the ITCZ leads to elevated VOC concentrations in the UTLS region. This also results in a depletion of lower stratospheric $\mathrm{O}_{3}$. We find that this is caused by a high destruction of $\mathrm{O}_{3}$ by phenoxy radicals and by the increased formation of $\mathrm{NO}_{x}$ reservoir species, which dampen the chemical production of $\mathrm{O}_{3}$. 